\title{
Systemic spreading of exogenous applied RNA biopesticides in the crop plant Hordeum vulgare
}

\author{
D. Biedenkopf ${ }^{1}$, T. Will ${ }^{2}$, T. Knauer ${ }^{3}$, L. Jelonek ${ }^{4}$, Alexandra Charlotte Ursula Furch ${ }^{5}$, T. Busche ${ }^{6}$ and A. Koch ${ }^{7 *}$ (D)
}

\begin{abstract}
Background: Small (s) RNA molecules are crucial factors in the communication between hosts and their interacting pathogens/pests that can modulate both host defense and microbial virulence/pathogenicity known as crosskingdom RNA interference (ckRNAi). Consistent with this, sRNAs and their double-stranded (ds) RNA precursors have been adopted to control plant diseases through exogenously applied RNA biopesticides, known as spray-induced gene silencing (SIGS). While RNA spray proved to be effective, the mechanisms underlying the transfer and uptake of SIGS-associated RNAs are inadequately understood. Moreover, the use of the SIGS-technology as a biopesticide will require the systemic spreading of dsRNA/siRNA signals.

Results: The integration of our findings strongly support the notion of long-distance spreading of SIGS-associated dsRNA and/or siRNA. In summary, our findings support the model that SIGS involves: (i) uptake of sprayed dsRNA by the plant (via stomata); (ii) transfer of apoplastic dsRNAs into the symplast (DCL processing into siRNAs); (iii) systemic translocation of siRNA or unprocessed dsRNA via the vascular system (phloem/xylem); (iv) uptake of apoplastic dsRNA or symplastic dsRNA/siRNA depending on the lifestyle/feeding behavior of the pathogen/pest.
\end{abstract}

Conclusions: Our findings are significant contributions to our mechanistic understanding of RNA spray technology, as our previous data indicate that SIGS requires the processing of dsRNAs by the fungal RNAi machinery.

Keywords: RNAi, RNA-based plant protection, Small RNAs, dsRNA, Exogenous RNA spray, SIGS, Cross-kingdom RNAi, Fusarium, Phloem, Barley stylectomy

\section{Background}

The vascular network of higher plants is composed of the phloem and xylem that pervades the whole organism from root to shoot and distributes nutrients and water [27, 44]. Sieve elements (SEs), companion cells (CCs) and phloem parenchyma cells (PPCs) are the three phloem elements involved in long-distance transport of photoassimilates in angiosperms [11, 45]. A high density of pore-plasmodesma units (PPUs) and ER coupling between $\mathrm{SE}$ and $\mathrm{CC}$ underline an intimate symplasmic connection $[16,28]$. The cross-walls between the SE-

\footnotetext{
*Correspondence: aline.koch@uni-hohenheim.de

${ }^{7}$ Institute for Phytomedicine, Hohenheim University, Otto-Sander-Strasse 5, 70559 Stuttgart, Germany

Full list of author information is available at the end of the article
}

modules become transformed into sieve plates, perforated by plasmodesmata (PD) modified into sieve pores, mediating long-distance transport of signalling molecules that play a pivotal role for the regulation of several developmental processes [26]. This non-cell-autonomous control involves the transfer of informational molecules such as proteins, mRNA and small RNAs [12]. Since the first detection of unspecified nucleic acids in the phloem sap in the late 1990s $[39,40]$, several studies demonstrated the systemic translocation of mRNA mediating non-cell autonomous control of plant development, defense and nutrient allocation via the phloem [12, 26]. However, decades ago scientists revealed RNA as the agent for systemic acquired gene silencing. They have shown delivery of RNA-based signals via the phloem pathway that affect

(c) The Author(s). 2020 Open Access This article is licensed under a Creative Commons Attribution 4.0 International License, which permits use, sharing, adaptation, distribution and reproduction in any medium or format, as long as you give appropriate credit to the original author(s) and the source, provide a link to the Creative Commons licence, and indicate if changes were made. The images or other third party material in this article are included in the article's Creative Commons licence, unless indicated otherwise in a credit line to the material. If material is not included in the article's Creative Commons licence and your intended use is not permitted by statutory regulation or exceeds the permitted use, you will need to obtain permission directly from the copyright holder. To view a copy of this licence, visit http://creativecommons.org/licenses/by/4.0/. 
gene expression at the whole-plant level by sequencespecific degradation of targeted mRNA [14, 34, 35]. These scientists were the first who linked systemic RNA signaling with a process known as RNA silencing.

RNA silencing (also known as RNA interference, RNAi) is a conserved and integral aspect of gene regulation mediated by small RNAs (sRNAs) that direct gene silencing on the level of transcription but also posttranscriptionally. At the transcriptional level, gene expression is inhibited via RNA-directed DNA methylation (RdDM) while at the post-transcriptional level (PTGS) direct mRNA interference causes inhibition of translation. Originally, RNA silencing is associated with protection against viral infection, control of epigenetic modifications, regulation of genome stability, curbing of transposon movement and regulation of heterochromatin formation [3, 19]. Besides its natural function, RNA silencing has emerged as a powerful genetic tool for scientific research over the past several years. It has been utilized not only in fundamental research for the assessment of gene function, but also in various fields of applied research, such as agriculture. In plants, RNA silencing strategies have the potential to protect host plants against predation or infection by pathogens and pests mediated by lethal RNA silencing signals generated in planta (for review see: [20, 24, 38, 47, 48]. Indeed, our results showed that transgenic Arabidopsis and barley (Hordeum vulgare) plants, expressing a 791 nucleotide (nt) dsRNA (CYP3RNA) targeting all three copies of the CYP51 gene ( $F g C Y P 51 A$, FgCYP51B, FgCYP51C) in $\mathrm{Fu}$ sarium graminearum $(\mathrm{Fg})$, inhibited fungal infection via a process designated as host-induced gene silencing (HIGS) [21, 33]. Moreover, we demonstrated that HIGSmediated targeting of the structural sheath protein (Shp) mandatory for aphid feeding, produced significantly lower levels of Shp mRNA compared to aphids feeding on wild-type (wt) plants [1].

In addition to the generation of RNA silencing signals in planta, plants can be protected from pathogens and pests by exogenously applied RNA biopesticides (known as sprayinduced gene silencing, SIGS) (for review see: [2, 4, 5, 9, 31]). Over the last decade, our research $[13,17,18,21,22,46]$ and the work of others have revealed the enormous potential of RNA-silencing strategies as a potential alternative to conventional pesticides for plant protection, regardless of how targetspecific inhibitory RNAs are applied (i.e. endogenously or exogenously).

Despite the promising potential of RNAi-based disease control and its benefits for agronomy and the ecosystem, the mechanisms underlying those technologies are inadequately understood. Understanding the uptake and translocation processes of non-coding RNAs is critical for its successful future application in the field. Application non-coding RNAs as biopesticides will require knowledge on the paths used by dsRNA/siRNA as signal. Previously, we have shown that fluorescent dsRNA is detected in the vascular tissue of barley after spraying the leaves with the $791 \mathrm{nt}$ long CYP3-dsRNA $\mathrm{A}_{488}$, directed against fungal CYP51 genes using a detached leaf assay that enabled us to assess fungal growth in distal (semi-systemic, non-sprayed) leaf segments [17].

In the present study, we demonstrated that aphids accumulate fluorescent dsRNA, when they feed on distal parts of barley leaves that were sprayed with dsRNA. Our study claimed to further investigate whether sprayed RNAs are translocated to the roots, thus, control of root colonizing pathogens can be achieved via SIGS. Indeed, we observed that spraying barley with a noncoding dsRNA has the potential to prevent plant roots from Fusarium infection. Summarizing our results we (i) found spray-induced gene silencing of an aphid mRNA target measured by qRT-PCR, (ii) visualized a fluorescent-labelled dsRNA in the phloem sap of barley using stylectomy (iii) profiled SIGS-derived siRNA in the phloem sap of barley by RNA-seq analysis (iv) detected SIGS-associated RNAs in barley roots using RT-PCR.

\section{Results \\ SIGS-mediated gene silencing in Sitobion avenae fed on barley leaves}

Mobile cell non-autonomous inhibitory RNAs that spread gene silencing into adjacent cells and tissues have been shown to move through the vascular system [23, 35, 49]. Previously, we demonstrated that aphids which fed on transgenic barley expressing dsRNA derived from the $\operatorname{Sh} p$ gene (Shp-dsRNA), produce significantly lower levels of $\operatorname{Sh} p$ mRNA compared to aphids feeding on wild-type (wt) plants [1]. Based on these previous data, we modified the setup for dsRNA application in order to demonstrate a semi-systemic transfer of the dsRNA. Therefore, we tested whether locally sprayed $491 \mathrm{nt}$ long Shp-dsRNA confers gene silencing in grain aphids feeding from distal, non-sprayed segments of the same barley leaves (Supp. Fig. 1). To this end, the upper part of detached leaves (local tissue) was sprayed with $20 \mathrm{ng}^{-1}$ Shp-dsRNA, while the lower part (distal tissue) was covered by a plastic tray to prevent direct dsRNA contact. After $48 \mathrm{~h}$, we placed aphids at the distal, non-sprayed part of the leaves in clip cages and led them feed on the phloem for $24 \mathrm{~h}$. Subsequently aphids were harvested and assessed for downregulation of the Shp target gene expression using qRT-PCR. The relative expression level of the aphid's Shp gene was reduced by almost $60 \%$ compared to aphids that fed on control leaves sprayed with Tris-EDTA (TE) buffer (Fig. 1), suggesting that the transfer of inhibitory RNA from the plant phloem sap to the insect was successful. 


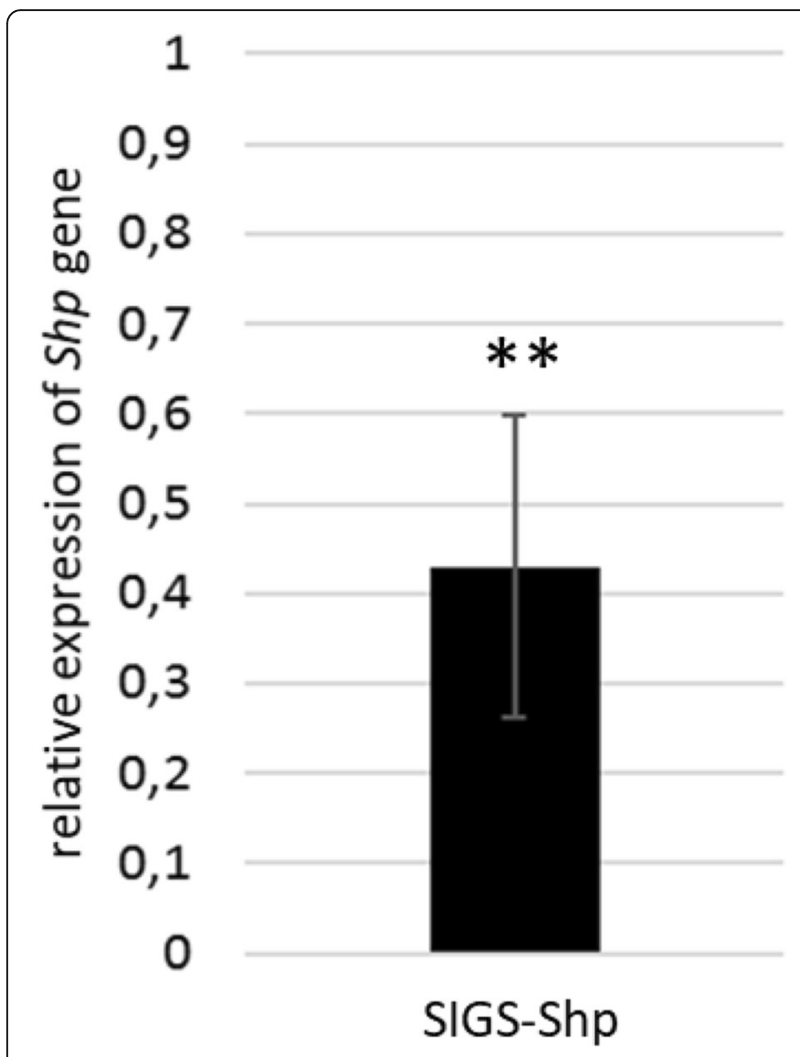

Fig. 1 Silencing of Shp gene in Sitobion avenae that fed on dsRNA sprayed barley leaves. Leaves were sprayed in a semi-systemic setup as previously described [17] with a final concentration of $20 \mathrm{ng} \mathrm{Hl}^{-1}$ dsRNA. cDNA was generated after total RNA extraction from aphids at 5 days of inoculation after dsRNA spray. The Shp gene silencing was measured via the $2^{-\Delta \Delta C t}$ method in which the expression of the respective Shp gene was normalized against the aphid reference gene 185 ribosomal RNA (GenBank APU27819), and this $\Delta$-Ct value was then normalized against the $\Delta$-Ct of the mock sprayed control. The reduction in Shp gene expression in the aphids that fed on ShpdsRNA sprayed leaves compared to the mock sprayed control was statistically significant. Error bars represent SE of three independent experiments each using 5-10 adult aphids for each treatment ${ }^{* *} p<$ 0.01 ; students t-test)

Transport of sprayed dsRNA in the phloem of barley Encouraged by the RNAi effects on the Shp target gene in phloem-sucking $S$. avenae, we investigated whether the sprayed Shp-dsRNA is translocated in the phloem and/or processed by the plant's silencing machinery. To this end, we used aphid stylectomy to gain access to pure phloem sap of barley leaves (Fig. 2 A-C). Stylectomy is commonly used to study a broad variety of physiological, mechanical and molecular properties of the plant phloem [37, 42, 43].

To further visualize the phloem-mediated transfer of sprayed Shp-dsRNA, it was labeled with the green fluorescent dye ATTO 488 (Shp-dsRNA ${ }_{\mathrm{A} 488}$ ) and sprayed onto barley leaves using the semi-systemic setup followed by stylectomy with $S$. avenae in the distal, non- sprayed leaf parts. Using confocal laser scanning microscopy, a green fluorescent signal was detected $24 \mathrm{~h}$ after feeding (48 $\mathrm{h}$ after spraying) and cutting at the stylet tip (Fig. 2 D). Together these data show that sprayed ShpdsRNA is transferred via the plant's phloem.

\section{RNA-seq profiling of stylectomy samples revealed SIGS- derived siRNAs}

We addressed the question whether the phloemtransferred Shp-dsRNA is stable during transport or alternatively at least partially processed into small interfering RNAs. To test this possibility, we profiled ShpdsRNA-derived siRNAs in the phloem sap after isolation using stylectomy. Small RNA sequencing (sRNA-seq) analysis revealed Shp-dsRNA-derived siRNA in distal (non-sprayed) leaf segments (Fig. 3). These data suggest that Shp-dsRNA-derived siRNAs also are processed by the plant's silencing machinery and systemically transferred via the phloem.

\section{Translocation of sprayed dsRNA from leaves to barley roots}

The RNA silencing signal can travel over long distances and trigger silencing in distant plant tissues [23, 32]. However, little is known about how exogenous applied dsRNAs and/or siRNAs are transported in the plant. To test whether there is wider systemic spreading of RNA silencing signals via the phloem and to further determine to what extend those sprayed RNAs are translocated within the plant we analysed the spreading of the sprayed dsRNA within intact barley plants. Towards this, we measured the amount of sprayed RNA in leaves, shoots and roots at different timepoints after spray application using qRT-PCR. To assess transport of sprayed dsRNA in systemic, non-sprayed plant tissue we used two-week old barley plants that were grown in filter paper. For the systemic setup, the plants were covered before spraying with a plastic tray leaving only the upper part/leaf tip (approximately $1 \mathrm{~cm}$ ) of the first leaf uncovered. Using this approach we found that the CYP3RNA translocate from the first (sprayed) leaf into the second leaf as well as the shoot tissue over time (Fig. 4), the amount of sprayed dsRNA decreased from $1 \mathrm{~d}$ to $3 \mathrm{~d}$ after spray (das) application in leaves and shoots. Interestingly, the amount of dsRNA within the roots increased from 1 das to 3 das (Fig. 5), indicating a translocation route from leaves to roots. However, to test whether the amount of transferred, SIGS-derived RNAs is sufficient to provoke target gene silencing, we inoculated the plants with $F g$ and measured the transcript level of FgCYP51 target genes in leaves, shoots and roots of infected plants (Fig. 6). Notably, we measured the strongest target gene silencing in the first leaf, the leaf that was initially spray treated. However, the 

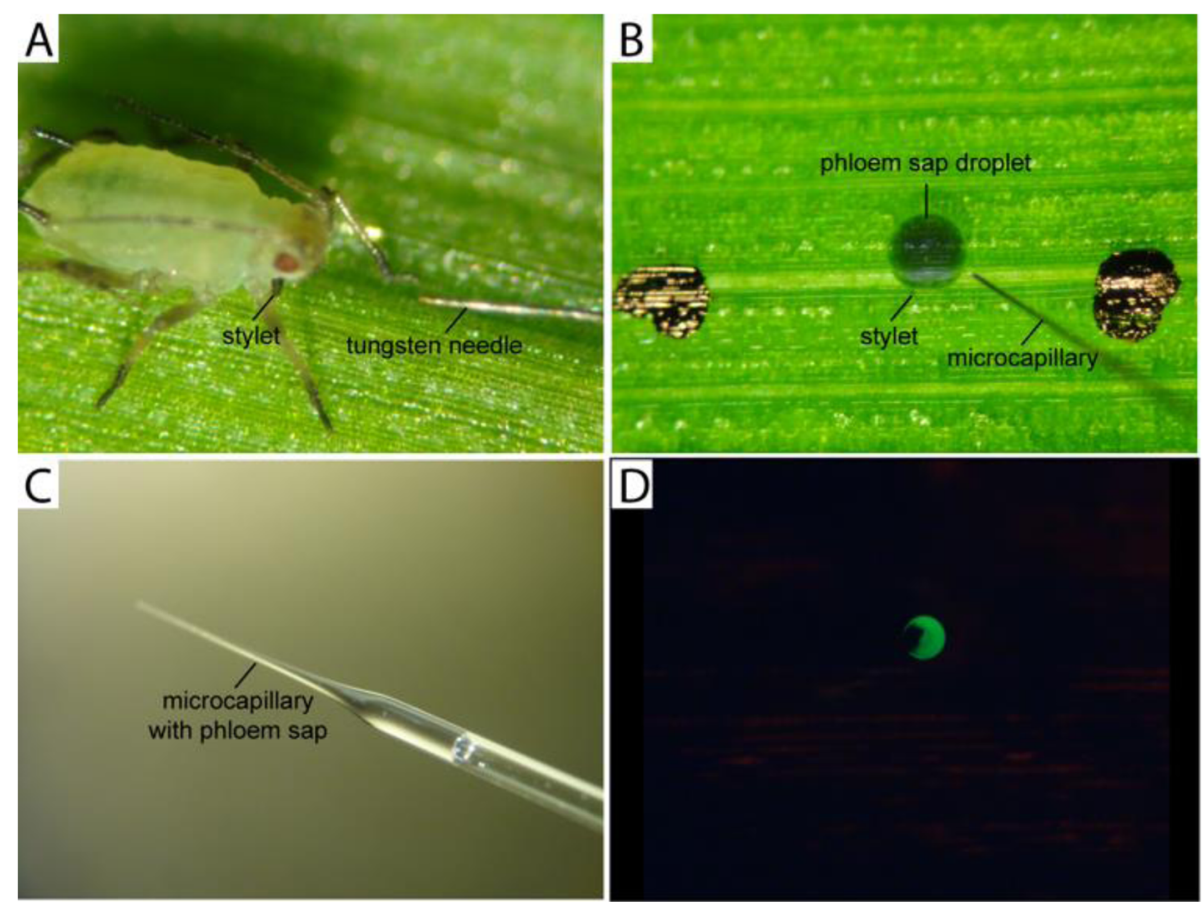

Fig. 2 Stylectomy technique applied for the barley-Sitobion avenae system. a Sitobion avenae feeding on a barley leaf shortly before cutting the mouthparts (stylet) with a tungsten needle connected to a microcautery device. $\mathbf{b}$ Injection of antimycotic, antibiotic and RNAse-inhibitor using a microcapillary at the beginning of the exudation period after overlaying with silicone oil. c Sampling of sieve-tube exudate from a cut aphid stylet under silicone oil with a microcapillary after an exudation period of $24 \mathrm{~h}$. $\mathbf{d}$ Stylectomy of ATTO 488 -labeled Shp-dsRNA $\mathrm{A}_{488}$ in sprayed barley leaves. Detection of Shp-dsRNA $A_{4488}$ (green) in the phloem sap droplet using stylectomy. Aphids were placed on non-sprayed leaf parts and stylectomy was performed $48 \mathrm{~h}$ after spray treatment with Shp-dsRNA 4488

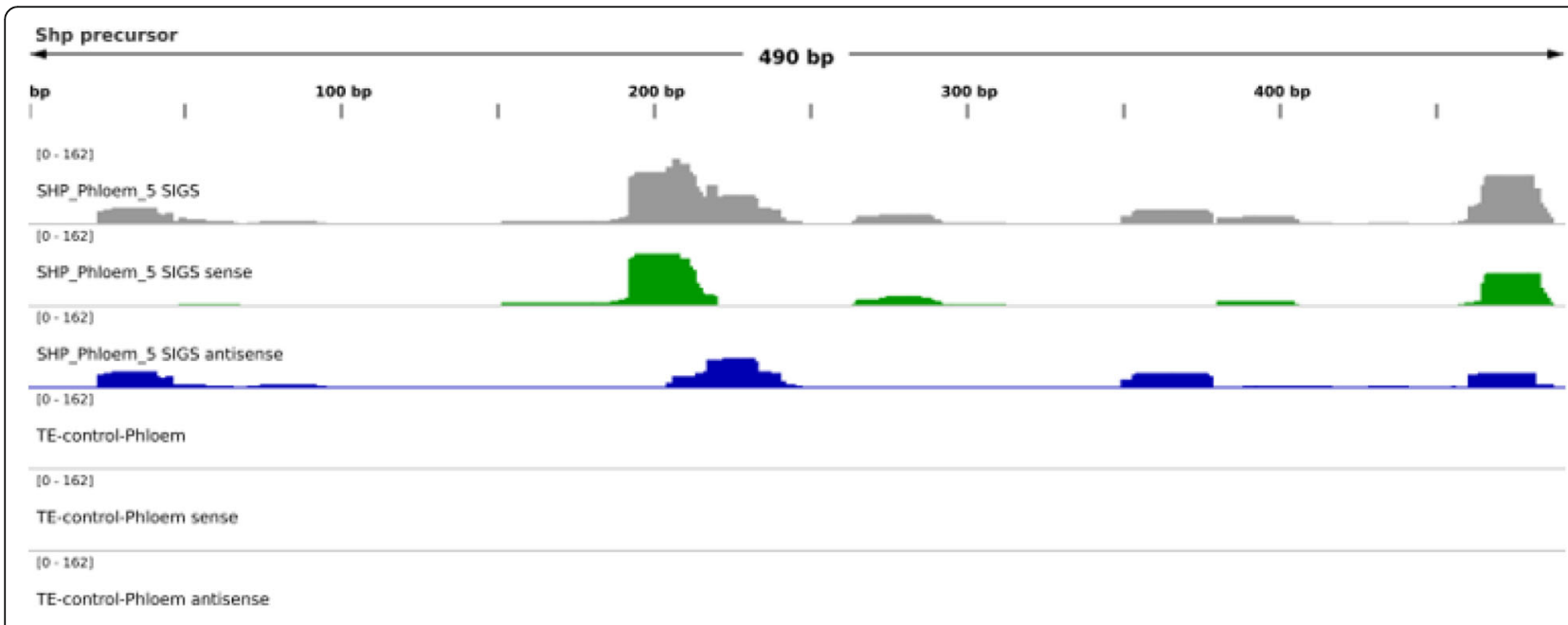

Genes

Shp

Fig. 3 Profiling of Shp-dsRNA-derived siRNAs in the phloem sap from barley leaves. Phloem sap was sampled by stylectomy. Total RNAs were isolated using a single cell RNA purification kit (Norgen Biotek Corp.). sRNA reads between 19 and 30 nt from Shp-dsRNA-sprayed and mocktreated barley leaves were mapped to Shp-dsRNA precursor [1]. Read coverage varied from 0 to 162 as indicated. Sequencing data are gained from 5 pooled separate phloem sap isolations experiments with a total sample amount of $10 \mu \mathrm{l}$ phloem sap from sprayed leaves and $10 \mu \mathrm{l}$ phloem sap from non-sprayed leaves, respectively 


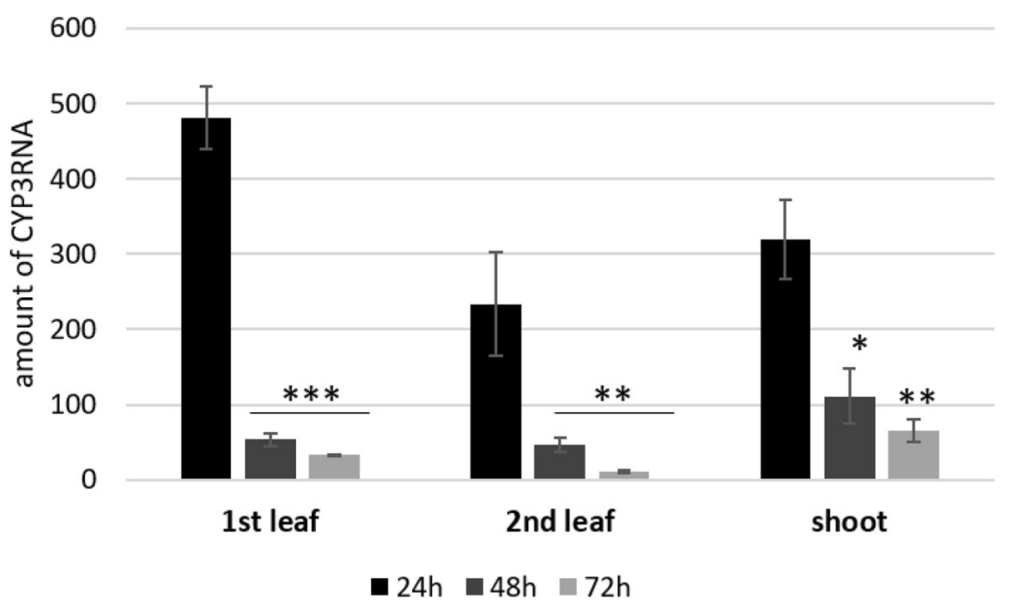

Fig. 4 Detection of CYP3RNA in barley leaves and shoots at different time points after spray application. Amount of CYP3RNA in the first (sprayed) leaf as well as non-sprayed second leaves and shoot tissue. The relative amount of sprayed CYP3RNA measured by qPCR decreased over time in leaves and increased in roots compared to mock-sprayed control leaves. Bars represent mean values \pm SEs of three independent experiments. The reduction of CYP3RNA vs. mock-sprayed leaves was statistically significant $\left({ }^{*} P<0.05\right.$; Student's t-test)

second leaf samples exhibited an overall target gene silencing of $80 \%$, which is still very high. In the analysed shoot and root tissue we found $50 \%$ silencing of the fungal CYP51 target genes. Together these data are consistent with our translocation observations, indicating that the transferred SIGS-associated RNAs can provoke silencing of their complementary target genes. Moreover, we found that $7 \mathrm{~d}$ after infection hypocotyls of plants sprayed with CYP3RNA developed less brownish lesions compared to TE-treated control plants suggesting that

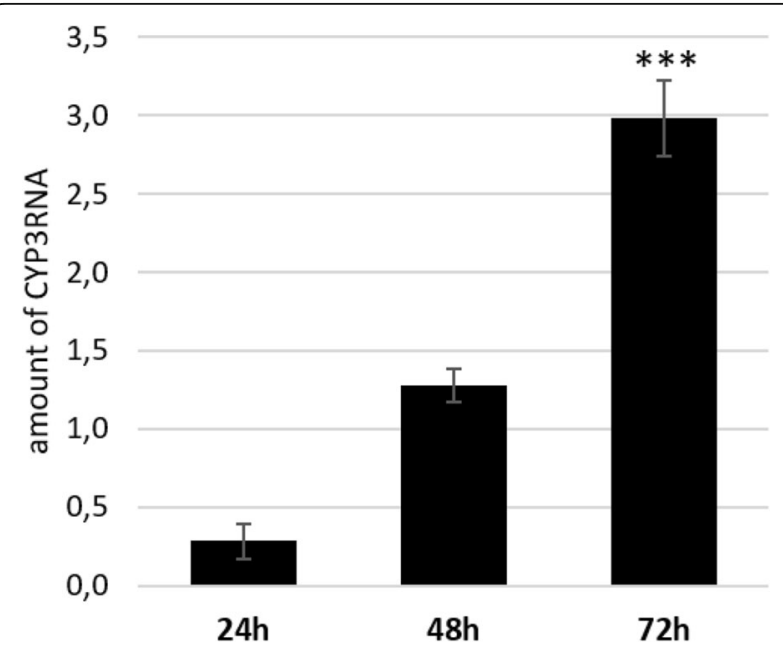

Fig. 5 Detection of CYP3RNA in barley roots at different time points after spray application. Amount of CYP3RNA in the roots of barley plants $24 \mathrm{~h}, 48 \mathrm{~h}$ and $72 \mathrm{~h}$ after spray treatment, respectively. The relative amount of sprayed CYP3RNA measured by qPCR decreased over time in leaves and increased in roots compared to mocksprayed control leaves. Bars represent mean values \pm SEs of three independent experiments. The reduction of CYP3RNA vs. mocksprayed leaves was statistically significant $\left({ }^{*} \mathrm{P}<0.05\right.$; Student's t-test) the amount of transferred RNA has the potential to prevent plants from $\mathrm{Fg}$ infection (Fig. 7).

\section{Discussion}

RNA sprays may provide an alternative strategy to avoid chemical pesticides and genetically modified crops for combating agricultural pests. However, systemic translocation of sprayed RNA biopesticides is critical for its successful future application in the field. To prove systemic spreading of SIGS-associated RNAs we decided to transfer a HIGS approach established for a phloem-sap sucking grain aphid $S$. avenae [1] to a SIGS proof-ofconcept study. To investigate uptake and transport of sprayed dsRNA, we tested whether locally sprayed ShpdsRNA confers gene silencing in S. avenae infecting distal, non-sprayed segments of barley leaves. To this end, we assessed whether the phloem-transported inhibitory RNA affect Shp target gene expression in aphids fed on the dsRNA-sprayed barley leaves using qRT-PCR. The relative expression level of the aphid's Shp gene was reduced by almost $60 \%$ compared to aphids that fed on buffer-sprayed controls (Fig. 1), suggesting that the transfer of inhibitory RNA from the plant phloem sap to the insect was successful. Next, we conducted another experiment to investigate whether the spray-applied Shp-dsRNA is translocated in the phloem and/or processed by the plant's silencing machinery. Specifically, we used aphid stylectomy, a widely used technique to study physiological, mechanical and molecular properties of the plant phloem [37, 42, 43]. Here, we used this technique to gain access to the phloem sap of barley leaves (Fig. 2). To further explore the phloem-mediated transfer of sprayed Shp-dsRNA, we sprayed fluorescent labelled Shp-dsRNA ${ }_{\mathrm{A} 488}$ onto barley leaves using a 


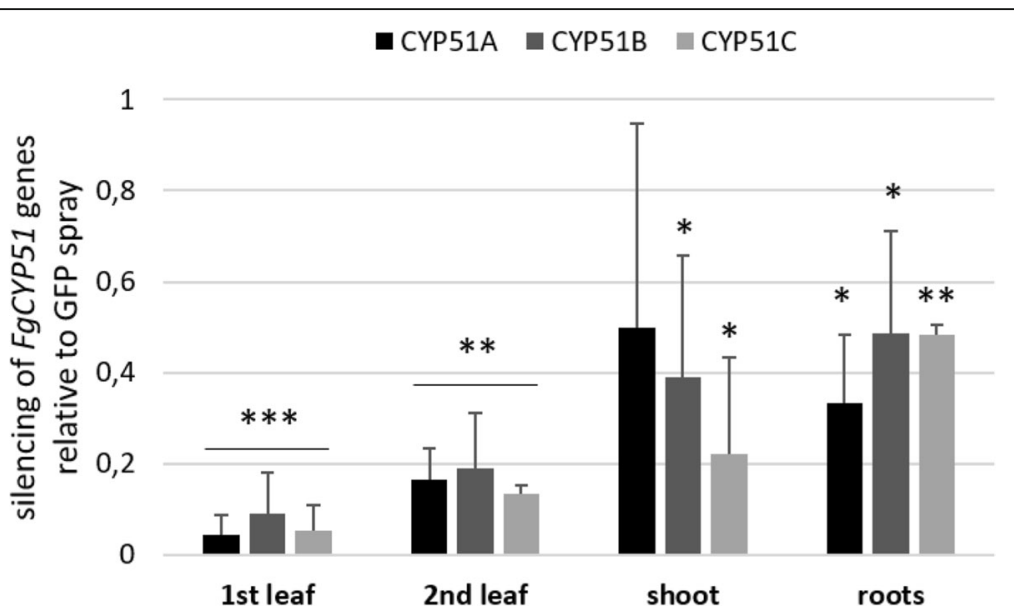

Fig. 6 Gene-specific qPCR analysis of fungal CYP51A, CYP51B, and CYP51C transcripts at 6 dpi (corresponding to 9 d after spraying). The FgCYP51 gene silencing was measured via the $2^{-\triangle \Delta C t}$ method in which the expression of the respective FgCYP51 gene was normalized against the reference genes EF1a (translation elongation-factor $1 \mathrm{a}$ ) and B-tubulin, and this $\Delta$-Ct value was then normalized against the $\Delta$-Ct of the GFP sprayed control. The reduction in fungal FgCYP51 gene expression on CYP3-dsRNA-sprayed leaves as compared with GFP-dsRNA-sprayed controls was statistically significant $\left({ }^{*} P<0.05,{ }^{* *} P<0.01,{ }^{* * *} P<0.001\right.$; Student's $t$ test)

systemic experimental design [17] following phloem sampling by stylectomy at the distal, non-sprayed leaf parts. Using CLSM, we detected a green fluorescent signal after cutting off the stylet tip of feeding aphids (Fig. 2 D). These results are consistent with our previous detection of the unprocessed $791 \mathrm{nt}$ precursor CYP3RNA in both local and distal tissue using northern blot analysis, showing that the long dsRNA is systemically translocated within the plant [17]. Moreover, investigation of longitudinal leaf sections revealed that the fluorescence was not confined to the apoplast but also was present in the symplast of phloem parenchyma cells, companion cells, and mesophyll cells, as well as in trichomes and stomata [17]. Supportively, apoplastic movement of RNA has been proposed, e.g. to explain how maternally expressed siRNAs could be transferred from the endosperm of developing seeds into the symplastically isolated embryo [29]. However, the mechanism by which the sprayed RNA overcomes the apoplastic-symplastic barrier is yet unknown.

Despite of the translocation of dsRNA, we found that also CYP3RNA-derived $21 \mathrm{nt}$ and $22 \mathrm{nt}$ siRNAs accumulated in the distal leaf segments, demonstrating that CYP3RNA was partly processed by the plant [17]. Therefore, we predict that SIGS-derived siRNAs would also translocate via the barley phloem. To test this possibility, we additionally profiled Shp-dsRNA-derived siRNAs using stylectomy. Small RNA-sequencing analysis revealed Shp-dsRNA-derived siRNA in distal (nonsprayed) leaf segments (Fig. 3). These data suggest that Shp-dsRNA-derived siRNAs also are processed by the plant's silencing machinery and are systemically transferred via the phloem. Importantly, we have previously shown that, when CYP3RNA ${ }_{4488}$-sprayed leaves were inoculated with $F g$ the fluorescent signal was also

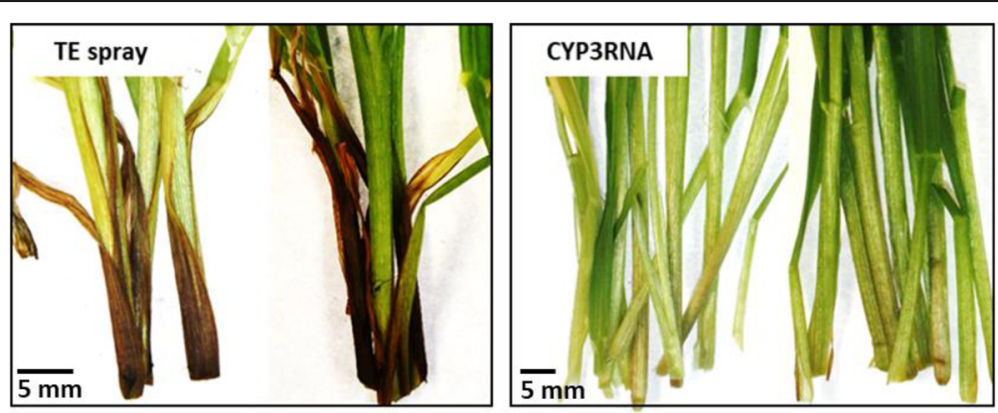

Fig. 7 SIGS-mediated control of Fg on barley plants sprayed with CYP3RNA. a Two-week-old barley plants cv. Golden Promise were sprayed with CYP3RNA (20 ng $\mathrm{LL}^{-1}$ ) or TE-buffer, respectively. $72 \mathrm{~h}$ later plants were inoculated with $2 \times 10^{4}$ conidia $\mathrm{mL}^{-1}$ of Fg. $7 \mathrm{~d}$ after infection hypocotyls of plants sprayed with CYP3RNA developed less brownish lesions compared to TE-treated control plants. Pictures were taken from two independent experiments 
detectable inside fungal conidia, germtubes, and fungal mycelium [17]. In addition or as an alternative to plantmediated gene silencing in the fungus, systemic translocation within the plant and accumulation by the fungus could also mediate direct processing of CYP3RNA by the fungus' gene silencing machinery to target fungal CYP51 genes. This finding that unprocessed long dsRNA is absorbed from leaf tissue has important implications for future disease control strategies based on dsRNA. It is very likely that processing of long dsRNA into many different inhibitory siRNAs by the fungus might explain higher gene silencing efficiency of SIGS compared to HIGS $[8,13,18]$ and might reduce the chance of pathogen resistance under field test conditions.

Consistent with our findings, there are several studies showing that mobile cell non-autonomous inhibitory RNAs that spread gene silencing into adjacent cells and tissues move through the vascular system [23, 35]. Grafting experiments revealed that siRNAs are detectable in tissues of DCL mutants that are defective for siRNA biogenesis [32]. This led to the speculation that siRNAs and not their long dsRNA precursors are the mobile silencing signals [6]. However, until now the exact molecular forms of mobile RNAs remain unclear [36]. Here we showed movement of sprayed dsRNA from barley leaves over stems to the root tissue within 3 days after spray treatment (Fig. 4). Moreover, we found that the transferred SIGS-associated RNAs confer target gene silencing in the respective tissues as well as $F g$ disease resistance (Fig. 7, [18]). Interestingly, we measured the highest silencing efficiency in the tissue that was either directly sprayed or near to the sprayed locus. In other words, it seemed that the amount and/or the nature of the mobile RNA determine the systemic silencing efficiency. In line with this, we measured the highest amount of dsRNA in leaves and detected low amounts of dsRNA in the roots (Fig. 4 and Fig. 5). Based on these findings, we predict a dilution effect that correlate with the distance to the initial spray site (or tissue). This is consistent with another study, where the authors confirmed the spreading of dsRNA from local to systemic tissue by 1 hour after rub-inoculation of dsRNA using semi-quantitative RT-PCR. Moreover, they showed that dsRNA levels continuously decreased in the local (treated) tissue from 3 days post inoculation (dpi) to $9 \mathrm{dpi}$ where dsRNA was no longer detectable [31]. More recently, Kaldis et al. [15] showed that exogenously applied dsRNA derived from the silencing suppressor HC-Pro and the coat protein genes of zucchini yellow mosaic virus (ZYMV) protect watermelon and cucumber against ZYMV and spread systemically over long distances in cucurbits [15].

In summary, our data suggest that sprayed dsRNAs are taken up by the plant, spread systemically via the plant vascular system, and are partially processed into
siRNAs by the plant's gene silencing machinery. As our results strongly support the notion of phloem-mediated long-distance movement of SIGS-associated dsRNA and/or siRNA, further research is needed to address central questions as: What are the exact uptake mechanisms that allow dsRNAs to enter plant tissue? How are dsRNA transported at the apoplast-symplast interface? How does the fungus take up SIGS-associated RNAs?

\section{Conclusion}

RNA-based plant protection strategies, such as exogenous application of RNA biopesticides (known as sprayinduced gene silencing; SIGS) may have high potential for agronomical applications. However, understanding the mechanistic basis (i.e. processing, translocation and uptake) of SIGS is critical for the successful implementation of this technology for future field application. Thus, our data provide significant knowledge on the translocation and uptake of exogenous applied dsRNA by the phloem sap sucking insect Sitobion avenae and the necrotrophic fungus Fusarium graminearum. Moreover, we showed that SIGS-associated RNAs that translocated to the barley roots inhibited fungal root infection. Of note, our data indicate that there is no production of secondary sRNAs, which may amplify the silencing signal as we observed a dilution effect of the sprayed RNAs that reached the root tissue.

\section{Methods}

Maintenance of plants and aphids

The spring barley (Hordeum vulgare) cultivar (cv.) Golden Promise (GP) was grown in a climate chamber under $16 \mathrm{~h}$ light photoperiod $\left(240 \mu \mathrm{mol} \mathrm{m}{ }^{-2} \mathrm{~s}^{-1}\right.$ photon flux density) at $18{ }^{\circ} \mathrm{C} / 14{ }^{\circ} \mathrm{C}$ (day/night) and $65 \%$ relative humidity. Grain aphids (Sitobion avenae) were reared on three-week-old barley plants in a climate chamber under the same conditions. To obtain synchronized insects, reproductive mature aphids were placed in clip cages (one aphid per cage) on GP plants for $24 \mathrm{~h}$. The adults were then removed, and the offspring were used for experiments as previously described $[10,41]$.

\section{dsRNA synthesis}

For spray experiments, the clone p7i-Ubi-Shp-RNAi that includes a partial sequence of the $3621 \mathrm{bp}$ Shp-cDNA (XM_001943863, ACYPI009881) of the pea aphid Acyrthosiphon pisum $(A p)$ was used as template for the synthesis of $491 \mathrm{nt}$ long Shp-dsRNA [1]. dsRNA was generated using MEGAscript RNAi Kit (Invitrogen) following MEGAscript ${ }^{\circ}$ protocols. Primer pairs T7_F and T7 R with T7 promoter sequence at the 5 end of both forward and reverse primers were designed for amplification of dsRNA (S1 Table). 


\section{Spray application of dsRNA}

Second leaves of 2-3-wk-old barley cv. GP were detached and transferred to square petri plates containing $1 \%$ water-agar. The dsRNA was diluted in $500 \mu \mathrm{l}$ water to a final concentration of $20 \mathrm{ng}^{-1}$. As a control, TRIS/EDTA (TE) buffer was used in a concentration corresponding to final concentration of the dsRNA sample. A typical RNA concentration after elution (see MEGAscript ${ }^{\oplus}$ protocols) was $500 \mathrm{ng}^{-1} \mathrm{l}^{-1}$ with a final TE buffer concentration of $400 \mu \mathrm{M}$ Tris-HCL and $40 \mu \mathrm{M}$ EDTA. Spraying of leaves was carried out using a spray flask as described [17]. Each plate containing 10 detached leaves were sprayed in a semi-systemic setup where lower leaf segments were covered with a plastic tray as described [17], with either Shp-dsRNA or TE buffer by giving 3-4 puffs, and subsequently kept at room temperature (RT). Forty-eight hours after spraying, aphids were placed on the non-sprayed part of each leaf using clip cages.

For the RNA translocation assays barley seedling were grown in petri dishes for 1 week. The seedlings were then placed into moist filter paper rolls and grown for 4 days before spraying the first leaf with $20 \mathrm{ng} \mathrm{Hl}^{-1}$ of CYP3RNA or GFP-dsRNA (control). To measure the amount of sprayed dsRNA in different tissues (first leaf, second leaf, shoot and root), samples were taken $24 \mathrm{~h}$, $48 \mathrm{~h}$ and $72 \mathrm{~h}$ after spray treatment of the first leaf. To analyse target gene silencing plants were inoculated with $\mathrm{Fg}$ after spray treatment and samples were taken 5 days after infection.

\section{Stylectomy and aphid sampling}

At $24 \mathrm{~h}$ after spray application of dsRNA, 20-30 mainly adult aphids (Sitobion avenae) were placed onto the upper surface of each leaf and allowed to feed for $24 \mathrm{~h}$. Following successful cauterization of the mouthparts with a microcautery device (CF-50, Syntech, [7]), each aphid stylet exuding phloem sap was marked with two small dots on the leaf surface and kept moist with a drop of DEPC water to prevent early occlusion. After cutting all aphid stylets, the DEPC water droplets were removed with a paper towel and the petri dish was subsequently flooded with silicone oil (M 200, Roth) to prevent evaporation of the sieve tube exudates. Due to the observation of sporadic bacterial and fungal contamination from the leaf surface, a mixture of antimycotic $(25 \mathrm{nl}$ Nystatin $5 \mathrm{mM})$, antibiotic $(25 \mathrm{nl}$ Tetracycline $5 \mathrm{mM})$, and $50 \mathrm{nl}$ RNAse Inhibtor (Invitrogen) (with traces of Bromophenol Blue for optical verification) was injected into each sieve tube sap sample at the beginning of the exudation phase to prevent degradation of RNA. By $24 \mathrm{~h}$ later, the sieve tube sap was collected using a microcapillary connected to a small syringe via a silicone tube with a side valve. Depending on the exudation time of the severed stylets, the sample amount reached up to $2 \mu$ per stylet over $24 \mathrm{~h}$. The samples of each treatment were pooled and stored at $-80^{\circ} \mathrm{C}$.

\section{Aphid transcript analysis}

To assess silencing of the Shp gene, mRNA expression analysis was performed using quantitative real-time PCR (qRT-PCR). Freshly extracted mRNA from 10 aphids was converted into cDNA using the QuantiTect Reverse Transcription Kit (Qiagen, Hilden, Germany) and $40 \mathrm{ng}$ of cDNA was used as the template for qRT-PCR in an Applied Biosystems 7500 FAST real-time PCR system. Each reaction comprised $7.5 \mu$ l SYBER Green JumpStart Taq ReadyMix (Sigma-Aldrich, Steinheim, Germany) and $0.5 \mathrm{pmol}$ of the gene-specific primers Shp-RNAqpcr-F1 and Shp-RNA-qpcr-R1 (Table S1). After initial heating to $95^{\circ} \mathrm{C}$ for $5 \mathrm{~min}$, the target was amplified by 40 cycles at $95^{\circ} \mathrm{C}$ for $30 \mathrm{~s}, 52^{\circ} \mathrm{C}$ for $30 \mathrm{~s}$ and $72{ }^{\circ} \mathrm{C}$ for $30 \mathrm{~s}$. Ct values were determined with the 7500 Fast software supplied with the instrument. Levels of Shp transcripts were determined via the $2^{-\Delta \Delta \mathrm{Ct}}$ method [25] by normalizing the amount of target transcript to the amount of the reference transcript $18 \mathrm{~S}$ ribosomal RNA (GenBank APU27819).

\section{Small RNA library production and sequence analysis}

RNA enriched for the sRNA fraction was purified from plant and fungal samples using the mirVana miRNA Isolation Kit (Life Technologies). Indexed sRNA libraries were constructed from these enriched sRNA fractions with the NEBNext Multiplex Small RNA Library Prep Set for Illumina (New England Biolabs) according to the manufacturer's instructions. Indexed sRNA libraries were pooled and sequenced on the Illumina HiSeq and NextSeq 500 platforms and the sequences sorted into individual datasets based on the unique indices of each sRNA library. The adapters and indices were trimmed with Cutadapt [30] version 1.16. Only reads with a length between $19 \mathrm{bp}$ and $30 \mathrm{bp}$ in the first pair of the paired end dataset were analysed. The reads were mapped to the shp-dsRNA vector sequence using bowtie2 [25] with "-very-sensitive -L 10" to identify sRNAs with a perfect match. The libraries contained 4.1 and 3.5 (control) million reads before trimming and filtering and 0.6 and 0.3 million reads after trimming and filtering.

\section{Confocal microscopy of fluorophore distribution}

Fluorescent labeling of dsRNA was performed using the Atto 488 RNA Labeling Kit (Jena Bioscience, Jena, Germany) following the manufacturer's instructions. Leaves were sprayed in a semi-systemic setup with the labeled dsRNA. Twenty-four $h$ after spraying of fluorescing dsRNA, aphids were placed onto the leaves and allowed to feed overnight. Twenty-four $h$ after 
infestation only stylets of the non-sprayed leaf area were cut. Phloem droplets that appeared on the stylet tips were imaged using a Leica TCS SP2 (Leica Microsystems, Wetzlar, Germany) equipped with a $75-\mathrm{mW}$ argon/krypton laser (Omnichrome, Chino, CA) and a water immersion objective (HCX APO L40x0.80 W U-Vl objective).

\section{Supplementary information}

Supplementary information accompanies this paper at https://doi.org/10. 1186/s41544-020-00052-3.

Additional file 1 Supplemental Figure 1: Workflow scheme to measure silencing of Shp gene in Sitobion avenae that fed on dsRNA sprayed barley leaves.

\section{Acknowledgments}

We thank C. Birkenstock, U. Schnepp and V. Weisel for excellent plant cultivation. We also thank Dr. Jens Steinbrenner for assisting in microscopic analyses. This work was supported by the Deutsche Forschungsgemeinschaft, Research Training Group (RTG) 2355 (project number 325443116) to AK

\section{Authors' contributions}

AK wrote the manuscript; AK and DB designed the study; DB, TK and TW conducted the experiments; AK, DB, TK, ACUF and $L$ analysed all data and drafted the figures. TK and TB conducted RNA-seq experiments and TB and $\sqcup$ performed bioinformatics analysis. The authors reviewed the final manuscript.

\section{Funding}

This work was supported by the Deutsche Forschungsgemeinschaft, Research Training Group (RTG) 2355 (project number 325443116) to AK.

\section{Availability of data and materials}

The datasets during and/or analysed during the current study available from the corresponding author on reasonable request.

\section{Ethics approval and consent to participate}

Not applicable.

\section{Consent for publication}

Not applicable.

\section{Competing interests}

The authors declare that they have no competing interests.

\section{Author details}

${ }^{1}$ Centre for BioSystems, Land Use and Nutrition, Institute of Phytopathology, Justus Liebig University, Heinrich-Buff-Ring 26, 35392 Giessen, Germany. ${ }^{2}$ Federal Research Centre for Cultivated Plants, Institute for Resistance Research and Stress Tolerance Julius Kuehn Institute, Erwin-Baur-Straße 27, 06484 Quedlinburg, Germany. ${ }^{3}$ Max Planck Institute for Chemical Ecology, Hans-Knoell-Strasse 8, 07745 Jena, Germany. ${ }^{4}$ Institute of Bioinformatics and Systems Biology, Justus Liebig University, Heinrich-Buff-Ring 58, 35392 Giessen, Germany. ${ }^{5}$ Institute of General Botany and Plant Physiology, Friedrich-Schiller-University, Dornburger Str. 159, 07743 Jena, Germany. ${ }^{6}$ Centre for Biotechnology - CeBiTec, Bielefeld University, Universitätsstraße 25, 33615 Bielefeld, Germany. ${ }^{7}$ Institute for Phytomedicine, Hohenheim University, Otto-Sander-Strasse 5, 70559 Stuttgart, Germany.

Received: 2 April 2020 Accepted: 7 July 2020

Published online: 19 August 2020

\section{References}

1. Abdellatef E, Will T, Koch A, Imani J, Vilcinskas A, Kogel KH. Silencing the expression of the salivary sheath protein causes transgenerational feeding suppression in the aphid Sitobion avenae. Plant Biotechnol J. 2015;13:84957.

2. Cai Q, He B, Kogel KH, Jin H. Cross-kingdom RNA trafficking and environmental RNAi - nature's blueprint for modern crop protection strategies. Curr Opin Microbiol. 2018;46:58-64.

3. Castel SE, Martienssen RA. RNA interference in the nucleus: roles for small RNAs in transcription, epigenetics and beyond. Nat Rev Genet. 2013;14:10012.

4. Dalakouras A, Wassenegger M, Dadami E, Ganopoulos I, Pappas ML, Papadopoulou K. Genetically Modifed Organism-Free RNA Interference: Exogenous. Plant Physiol. 2020;182(1):38-50. https://doi.org/10.1104/pp.19. 00570.

5. Dubrovina AS, Kiselev KV. Exogenous RNAs for gene regulation and plant resistance. Int J Mol Sci. 2019;20(9):2282.

6. Dunoyer P, Melnyk C, Molnar A, Slotkin RK. Plant Mobile small RNAs. Cold Spring Harb Perspect Biol. 2013;5:017897.

7. Fisher DB, Frame JM. A guide to the use of the exuding-stylet technique in phloem physiology. Planta. 1984;161:385-93.

8. Gaffar F, Imani J, Karlovsky JP, Koch A, Kogel KH. Various components of the RNAi pathway are required for conidiation, ascosporogenesis, virulence, DON production and SIGS-mediated fungal inhibition by exogenous dsRNA in the head blight pathogen Fusarium graminearum. Front Microbiol. 2019. https://doi.org/10.3389/fmicb.2019.01662.

9. Gaffar FY, Koch A. Catch me if you can! RNA silencing-based improvement of antiviral plant immunity. Viruses. 2019;11:673.

10. Gaupels F, Buhtz A, Knauer T, Deshmukh S, Waller F, van Bel AJE, et al. Adaptation of aphid stylectomy for analyses of proteins and mRNAs in barley phloem sap. J Exp Bot. 2008;59:3297-306.

11. Hafke JB, van Amerongen J-K, Kelling F, Furch ACU, Gaupels F, van Bel AJE. Thermodynamic battle for photosynthate acquisition between sieve tubes and adjoining parenchyma in transport phloem. Plant Physiol. 2005;138:1527-37.

12. Ham BK, Lucas WJ. Phloem-Mobile RNAs as systemic signaling agents. Annu Rev Plant Biol. 2017;28:173-95.

13. Höfle L, Shrestha A, Werner BT, Jelonek L, Koch A. Study on the efficacy of dsRNAs with increasing length targeting Fusarium graminearum CYP51 genes comparing HIGS and SIGS approaches. RNA Biol. 2020;17(4):463-73. https://doi.org/10.1080/15476286.2019.1700033.

14. Jorgensen RA. Cosuppression, flower color patterns,and metastable gene expression states. Science. 1995;268:686-91.

15. Kaldis A, Berbati M, Melita O, Reppa C, Holeva M, Otten P, et al. Exogenously applied dsRNA molecules deriving from the zucchini yellow mosaic virus (ZYMV) genome move systemically and protect cucurbits against ZYMV. Mol Plant Pathol. 2018:19:883-95.

16. Kempers R, Ammerlaan A, van Bel AJE. Symplasmic constriction and ultrastructural features of the sieve element/companion cell complex in the transport phloem of apoplasmically and symplasmically phloem-loading species. Plant Physiol. 1998;116:271-8.

17. Koch A, Biedenkopf D, Furch ACU, et al. An RNAi-based control of Fusarium graminearum infections through spraying of long dsRNAs involves a plant passage and is controlled by the fungal silencing machinery. PLoS Pathog. 2016;12:e1005901.

18. Koch A, Höfle L, Werner BT, Imani J, Schmidt A, Jelonek L, et al. SIGS vs HIGS: a study on the efficacy of two dsRNA delivery strategies to silence fusarium FgCYP51 genes in infected host and non-host plants. Mol Plant Pathol. 2019. https://doi.org/10.1111/mpp.12866.

19. Koch A, Kang HG, Steinbrenner J, Dempsey DA, Klessig DF, Kogel KH. MORC proteins: novel players in plant and animal health. Front Plant Sci. 2017:18:1720.

20. Koch A, Kogel KH. New wind in the sails: improving the agronomic value of crop plants through RNAi-mediated gene silencing. Plant Biotechnol J. 2014:12:821-31.

21. Koch A, Kumar N, Weber L, Keller H, Imani J, Kogel KH. Host-induced gene silencing of cytochrome P450 lanosterol C14a-demethylase-encoding genes confers strong resistance to fusarium spec. Proc Natl Acad Sci U S A. 2013; 110:19324-9.

22. Koch A, Stein E, Kogel KH. RNA-based disease control as a complementary measure to fight fusarium fungi through silencing of the azole target cytochrome P450 Lanosterol C-14 a-demethylase. Eur J Plant Pathol. 2018; 152:1003-10. https://doi.org/10.1007/s10658-018-1518-4.

23. Lewsey MG, Hardcastle TJ, Melnyk CW, Molnar A, Valli A, Urich MA, et al. Mobile small RNAs regulate genome-wide DNA methylation. Proc Natl Acad Sci U S A. 2016;113:801-10. 
24. Liu S, Jaouannet M, Dempsey DA, Imani J, Coustau C, Kogel K-H. RNA-based technologies for insect control in plant production. Biotechnol Adv. 2019; 107463

25. Livak KJ, Schmittgen TD. Analysis of relative gene expression data using real-time quantitative PCR and the 2(-Delta C(T)) method. Methods (San Diego, Calif). 2001;25:402-8.

26. Lough TJ, Lucas W. Integrative plant biology: role of phloem long-distance macromolecular trafficking. Annu Rev Plant Biol. 2006:57:203-32.

27. Lucas WJ, Groover A, Lichtenberger R, et al. The plant vascular system: evolution, development and functions. J Integr Plant Biol. 2013;55:294-388.

28. Martens HJ, Roberts AG, Oparka KJ, Schulz A. Quantification of plasmodesmatal endoplasmic reticulum coupling between sieve elements and companion cells using fluorescence redistribution after photobleaching. Plant Physiol. 2006;142:471-80.

29. Martienssen RA. Heterochromatin, small RNA and post-fertilization dysgenesis in allopolyploid and interploid hybrids of Arabidopsis. New Phytol. 2010;186:46-53.

30. Martin M. Cutadapt removes adapter sequences from high-throughput sequencing reads. EMBnet. J. 2011:17:10-2.

31. Mitter N, Worrall EA, Robinson KE, et al. Clay nanosheets for topical delivery of RNAi for sustained protection against plant viruses. Nature Plants. 2017;3: 16207.

32. Molnar A, Molnar A, Melnyk CW, Bassett A, Hardcastle TJ, Dunn R, et al. Small silencing RNAs in plants are mobile and direct epigenetic modification in recipient cells. Science. 2010;328:872-5.

33. Nowara D, Schweizer P, Gay A, Lacomme C, Shaw J, Ridout C, et al. HIGS: Host-induced gene silencing in the obligate biotrophic fungal pathogen Blumeria graminis. Plant Cell. 2010;22:3130-3141.

34. Palauqui JC, Elmayan T, De Borne FD, Crete P, Charles C, Vaucheret $\mathrm{H}$. Frequencies, timing, and spatial patterns of co-suppression of nitrate reductase and nitrite reductase in transgenic tobacco plants. Plant Physiol. 1996:112:1447-56

35. Palauqui JC, Elmayan T, Pollien JM, Vaucheret $\mathrm{H}$. Systemic acquired silencing: transgene-specific posttranscriptional silencing is transmitted by grafting from silenced stocks to non-silenced scions. EMBO J. 1997;16:473845.

36. Parent JS, Martínez de Alba AE, Vaucheret $H$. The origin and effect of small RNA signaling in plants. Front Plant Sci. 2012:9:179.

37. Peel AJ. Investigations with aphid stylets into the physiology of the sieve tube. In: Zimmerman MH, Milburn JA, editors. Transport in plants 1 phloem transport. 1st ed. Berlin Heidelberg New York: Springer; 1975. p. 171-95.

38. Qi, T, Guo J, Peng H, Liu P, Kang Z, Guo J. Host-induced gene silencing: A powerful strategy to control diseases of wheat and barley. Int J Mol Sci. 2019;20. https://doi.org/10.3390/ijms20010206.

39. Ruiz-Medrano R, Xoconostle-Cázares B, Lucas WJ. Phloem long-distance transport of mNACP mRNA: implications for supracellular regulation in plants. Development. 1999;126:4405-19.

40. Sasaki T, Chino M, Hayashi H, Fujiwara T. Detection of several mRNA species in rice phloem sap. Plant Cell Physiol. 1998;39:895-7.

41. Schmitz A, Anselme C, Ravallec M, Rebuf C, Simon JC, Gatti JL, et al. The cellular immune responses of the pea aphid to foreign intrusion and symbiotic challenge. PLoS One. 2012;7:e42114

42. Thompson GA, Van Bel AJE. Phloem: molecular cell biology, systemic communication, biotic interactions. Oxford: Wiley-Blackwell; 2012.

43. Turgeon R, Wolf S. Phloem transport: cellular pathways and molecular trafficking. Annu Rev Plant Biol. 2009;60:207-21.

44. van Bel AJE, Furch ACU, Hafke JB, Knoblauch M, Patrick JW. (questions) on phloem biology. 2. Mass flow, molecular hopping, distribution patterns and macromolecular signalling. Plant Sci. 2011;181:325-30.

45. van Bel AJE. Interaction between sieve element and companion cell and the consequences for photoassimilate distribution. Two structural hardware frames with associated physiological software packages in dicotyledons? J Exp Bot. 1996;47:1129-40.

46. Werner BT, Gaffar FY, Schuemann J, Biedenkopf D, Koch A. RNA-spraymediated silencing of Fusarium graminearum $A G O$ and DCL genes improve barley disease resistance. Front Plant Sci. 2020;11:476.

47. Yin C, Hulbert S. Host induced gene silencing (HIGS), a promising strategy for developing disease resistant crops. Gene Technol. 2015;4:130.
48. Zhang J, Khan SA, Heckel DG, Bock R. Next-generation insect-resistant plants: RNAi-mediated crop protection. Trends Biotechnol. 2017;35:871-82

49. Zhang T, Zhao Y-L, Zhao J-H, Wang S, Jin Y, Chen Z-Q, et al. Cotton plants export microRNAs to inhibit virulence gene expression in a fungal pathogen. Nat Plants. 2016;2:16153.

\section{Publisher's Note}

Springer Nature remains neutral with regard to jurisdictional claims in published maps and institutional affiliations.
Ready to submit your research? Choose BMC and benefit from:

- fast, convenient online submission

- thorough peer review by experienced researchers in your field

- rapid publication on acceptance

- support for research data, including large and complex data types

- gold Open Access which fosters wider collaboration and increased citations

- maximum visibility for your research: over $100 \mathrm{M}$ website views per year

At BMC, research is always in progress.

Learn more biomedcentral.com/submissions 